\title{
Developmental potential of surplus morulas with delayed and/or incomplete compaction after freezing-thawing procedures
}

Ni-Chin Tsai ${ }^{1,2}$, Yu-Ting Su' ${ }^{1}$ Yu-Ju Lin ${ }^{1}$, Hsin-Ju Chiang ${ }^{1}$, Fu-Jen Huang ${ }^{1}$, Fu-Tsai Kung ${ }^{1,3}$ and Kuo-Chung Lan La $^{1,4^{*}}$

\begin{abstract}
Background: Morulas with delayed growth sometimes coexist with blastocysts. There is still limited evidence regarding the optimal disposal of surplus morulas. With the advancement of vitrification, the freezing-thawing technique has been widely applied to zygotes with 2 pronuclei, as well as embryos at the cleavage and blastocyst stages. The freezing of morulas, however, has rarely been discussed. The purpose of this study was to investigate whether these poor-quality and slow-growing morulas are worthy of cryopreservation.

Methods: This is a retrospective, observational, proof-of-concept study. A total of 1033 day $5 / 6$ surplus morulas were cryopreserved from January 2015 to December 2018. The study included 167 women undergoing 180 frozen embryo transfer cycles. After the morulas underwent freezing-thawing procedures, their development was monitored for an additional day. The primary outcome was the blastocyst formation rate. Secondary outcomes were clinical pregnancy rate, live birth rate and abortion rate.

Results: A total of 347 surplus morulas were thawed. All studied morulas showed delayed compaction (day $5, n=329$; day $6, n=18)$ and were graded as having low $(M 1, n=54)$, medium $(M 2, n=138)$ or high $(M 3, n=155)$ fragmentation. The post-thaw survival rate was $79.3 \%$. After 1 day in extended culture, the blastocyst formation rate was 66.6\%, and the top-quality blastocyst formation rate was $23.6 \%$. The day 5 morulas graded as M1, M2, and M3 had blastocyst formation rates of $88.9,74.0$, and $52.8 \%(p<0.001)$, respectively, and the top-quality blastocyst formation rates were $64.8,25.2$, and $9.0 \%(p<0.001)$, respectively. The clinical pregnancy rate was $33.6 \%$.

Conclusions: The post-thaw blastocyst formation rate was satisfactory, with approximately one-half of heavily fragmented morulas (M3) developing into blastocysts. Most of the poor-quality morulas were worth to freeze, with the reasonable goal of obtaining pregnancy and live birth. This alternative strategy may be a feasible approach for coping with poor-quality surplus morulas in non-PGS (preimplantation genetic screening) cycles.
\end{abstract}

Keywords: Blastocyst formation, Fragmentation, Frozen embryo transfer, Slow developing morulas, Surplus morulas, Vitrification

\footnotetext{
* Correspondence: lankuochung@gmail.com

'Department of Obstetrics and Gynecology, Kaohsiung Chang Gung Memorial Hospital and Chang Gung University College of Medicine, 123 Ta-Pei Road, Niao-Sung District, Kaohsiung city, Taiwan

${ }^{4}$ Center for Menopause and Reproductive Medicine Research, Kaohsiung

Chang Gung Memorial Hospital and Chang Gung University College of

Medicine, Kaohsiung, Taiwan

Full list of author information is available at the end of the article
}

C The Author(s). 2019 Open Access This article is distributed under the terms of the Creative Commons Attribution 4.0 International License (http://creativecommons.org/licenses/by/4.0/), which permits unrestricted use, distribution, and reproduction in any medium, provided you give appropriate credit to the original author(s) and the source, provide a link to the Creative Commons license, and indicate if changes were made. The Creative Commons Public Domain Dedication waiver (http://creativecommons.org/publicdomain/zero/1.0/) applies to the data made available in this article, unless otherwise stated. 


\section{Background}

Current sophisticated culture systems and freezingthawing procedures have enhanced the application of blastocyst culturing and frozen embryo transfer (FET) $[1,2]$. Blastocyst culturing can be used to select embryos that have undergone genome activation [3], and it avoids the risk of transferring potentially arrested embryos or high-order embryos. Morulas with delayed growth sometimes coexist with blastocysts, and surplus morulas are often present. Slow-developing embryos are placed in a low priority queue for transfer selection. There is still limited evidence regarding the optimal disposal of surplus morulas; options include fresh transfer, extended culture and transfer in subsequent FET cycles, among others (ex. discarding, which would be controversial) $[4,5]$.

The vitrification technique has been widely applied in zygotes with 2 pronuclei, 8-cell embryos, and blastocyst embryos, but little attention has been given to morulas in previous literature, especially concerning poor-quality morulas after vitrification. Few studies to date have focused on the developmental potential or freezingthawing outcomes of embryos derived from the morula stage [3-10]. The survival rate of human day 4 morulas after freezing and thawing has been examined in a study addressing the morphological alterations and their applications in embryo selection [10]. The freezing-thawing strategy for surplus morulas at our institution was modified after 2015. Previously, after fresh blastocyst transfer, the morulas with delayed growth were cultivated until they reached the blastocyst stage or were cryopreserved. At present, to determine their growth potential, surplus morulas were thawed 1 day before FET. For the infertile couples, cryopreserving surplus morulas at the same time that blastocysts are cryopreserved is plausible, and they did not pay extra fees for that process at our institution.

Fragmentation has been associated with poor blastocyst formation and implantation rates, as well as chromosomal abnormalities [3, 11-14]. Little is known about the outcomes resulting from the use of pervasive fragmented morulas in fresh and FET cycles. The effects of delayed compaction and fragmentation on the developmental capacity of morulas in fresh cycles have been determined [9]; the finding was consistent with our experiences $[15,16]$, except for the day 5 heavily fragmented morulas, which had a low blastocyst formation rate in our previous observation. To our knowledge, no study to date has reported the postthaw BFR of morulas with either delayed compaction or heavy fragmentation.

The purpose of this study was to determine whether these poor-quality and slow-growing morulas are worthy of cryopreservation by exploring their developmental capacity after freezing-thawing procedures.

\section{Methods}

This is a retrospective, observational, and proof-ofconcept study. A total of 1033 day $5 / 6$ surplus morulas were cryopreserved from January 2015 to December 2018. Couples with vitrified surplus morulas who had returned for at least one FET cycle were included. The study included a total of 167 women undergoing 180 FET cycles. All couples completed the standard infertility workup; couples were not excluded based on age, sperm parameters or causes of infertility.

\section{Patient preparation in stimulated cycles, embryo management and embryo culture}

The protocols used for controlled ovarian hyperstimulation, oocyte retrieval and embryo culture have been described previously $[15,16]$. Briefly, women undergoing the GnRH antagonist protocol received an additional $0.25 \mathrm{mg} /$ day $\mathrm{GnRH}$ antagonist (Ganirelix acetate: $0.25 \mathrm{mg}$, MSD; or Cetrorelix acetate: $0.25 \mathrm{mg}$, Serono), beginning when one leading follicle reached $\geq 14 \mathrm{~mm}$ in diameter and ending on the day of human chorionic gonadotropin (hCG) injection. Gonadotropin doses were adjusted during each cycle based on individual responses, which included serum estradiol (E2) concentration and sonographic monitoring of follicular growth. Following the maturation of two additional follicles, each $\geq 18 \mathrm{~mm}$ in diameter, recombinant hCG (Ovidrel; Merck, Serono, Modugno, Italy) and/or GnRH-agonist (Decapeptyl, Ferring $\mathrm{GmbH}$ ) was administered. Oocytes were retrieved $36-38 \mathrm{~h}$ later by transvaginal aspiration under ultrasound guidance.

Standard IVF/ICSI procedures were used for oocyte fertilization. Fertilization was confirmed 16 to $18 \mathrm{~h}$ subsequent to IVF or ICSI. The embryos were evaluated on days 1, 2, 3 and 5. Embryos were cultured in $\mathrm{G}^{\text {тм }}$ medium (Vitrolife Sweden AB, Vastra Frolunda, Sweden) on days $1-3$ and in $\mathrm{G}^{\mathrm{mm}}$ medium (Vitrolife Sweden AB) on days 3-5 or 6. The incubator (Thermo Scientific HERACELL 150i) maintained the $\mathrm{O}_{2}$ level at 5\% and the culture medium $\mathrm{pH}$ at $7.27 \pm 0.07$ [17], and the $\mathrm{CO}_{2}$ was at approximately $6.3 \%$ per the recommendation of the media provider (Vitrolife Sweden).

Extending embryo culture to the blastocyst stage was performed if there were three or more good quality 8cell embryos on day 3. The top-quality embryos were selected by experienced embryologists and then were given priority for fresh cycle transfer.

The morula vitrification method was identical to the method used for blastocyst vitrification [18-20]. Because all studied morulas had delayed compaction, vitrification was performed on day 5 or 6 . A single team of embryologists coordinated all the procedures, thereby ensuring that the culture protocols and the embryo freezing-thawing procedures were consistent and standardized. 


\section{Embryo grading}

Morulas were defined as embryos containing $\geq 16$ blastomeres that were over $50 \%$ compacted. Morulas/compact stage embryos were graded using a modification of the simplified SART (Society for Assisted Reproductive Technology) embryo scoring system [21]. Each morula was scored according to its degree of compaction and fragmentation. Morula 1 (M1) was defined as a top-quality morula, with $>90 \%$ of its cell mass compacted and $<10 \%$ fragmentation. M2 has $70-90 \%$ compaction and $10-30 \%$ fragmentation, and M3 has 50-70\% compaction and > $30 \%$ fragmentation.

Blastocysts were graded according to the Gardner \& Schoolcraft system [22], which is based on the degree of blastocyst expansion and the morphological appearances of the inner cell mass and the trophectoderm cells. Topquality blastocysts were defined as 3AA, 4AA, 5AA or 6AA.

A consensus of grades for the embryos was reached by two experienced embryologists who used the same criteria. If discordance occurred, there would be a meeting to produce a final decision.

\section{Endometrial preparation for frozen embryo transfer and embryo thawing}

The endometrium was prepared either by artificial hormone replacement or by natural cycling. The embryos were transferred on day 6 of progesterone administration.

Morulas were warmed using a two-step dilution with sucrose [18] and then returned to $\mathrm{G}^{\mathrm{m}}{ }^{\mathrm{m}}$ medium for further culture until transfer. Laser-assisted hatching was performed $5 \mathrm{~min}$ after thawing [23, 24]. Assisted hatching with the diode laser system (FERTILASE; MTM Medical Technologies, Montreux, Switzerland) and short irradiation exposure times (4 m-second) were applied. A split of approximately one-quarter to one-third of the circumference of the zona pellucida was made. The morphological evolution and development of the embryos were then recorded. Morulas that failed to show changes consistent with recovery and those that became atrophic were discarded.

\section{Outcome analysis}

An embryo was determined to have progressed to the blastocyst stage if blastulation had occurred and the inner cell mass was visible. The BFR and the top-quality BFR were analyzed.

All women were followed regularly until pregnancy outcomes were confirmed. Pregnancy was confirmed by detecting $\beta$-hCG in the urine 2 weeks after transfer. Biochemical pregnancy was defined as the absence of an identifiable pregnancy on ultrasound examination in combination with a positive urine or serum $\beta$-hCG test [25]. Clinical pregnancy was defined as the identification of at least one gestational sac via ultrasound at 6-7 weeks of gestation [25]. Ongoing pregnancy was defined as a viable pregnancy beyond 12 gestational weeks. Abortion was defined as a pregnancy that was terminated spontaneously before 12 gestational weeks. Live birth was defined as the delivery of a viable fetus beyond 23 gestational weeks. The implantation rate was defined as the number of gestational sacs divided by the number of embryos transferred.

\section{Statistical analysis}

Continuous data are given as the mean \pm standard deviation (SD). Student's t-test was used to compare continuous data. Categorical variables, reported as proportions, were compared using the chi-square or Fisher's exact test, as appropriate. Logistic regression analysis was performed for multivariate analysis. All tests of significance were two-tailed, with $p<0.05$ defined as being statistically significant. All statistical analyses were performed with SPSS for Windows version 18.

\section{Results \\ Embryo post-thaw survival conditions and blastocyst formation rates}

During the 4-year study period, a total of 1033 day $5 / 6$ surplus morulas (M1, $n=32,12.8 \%$; M2, $n=426,41.2 \%$; M3, $n=475,46 \%)$ were cryopreserved. Of these, 347 (33.6\%) surplus morulas (day $5, n=329$; day $6, n=18$ ) were thawed. A total of 167 women who were undergoing 180 FET cycles from January 2015 to December 2018 were included. The mean age of the patients was $35.8 \pm 3.8$ years. Of the thawed morulas, $84.5 \%$ were initially graded as being of poor quality (over $10 \%$ fragmentation) at the fresh cycle. The post-thaw survival rate of morulas was $79.3 \%$. After 1 day in extended culture, the BFR was $66.6 \%$, and the topquality BFR was $23.6 \%$ (Table 1 ). The post-thaw morula atrophy rate (i.e., morulas unavailable for transfer) was $20.7 \%$ (72/347). Of these 72 atrophic morulas, 17 (23.6\%) were graded as M2, and 54 (75\%) were graded as M3. The cycle cancellation rate, during which no thawed embryos could be transferred, was $5.0 \%(9 / 180)$.

The day 5 morulas graded as M1, M2, and M3 had BFRs of $88.9,74.0$, and $52.8 \%(p<0.001)$, respectively, and they had top-quality blastocyst formation rates of $64.8,25.2$, and $9.0 \%(p<0.001)$, respectively. None of the day 6 morulas were graded as M1. The top-quality BFR for the day 6 morulas was 5.6\% (1/18) (Table 2).

Regression analysis was employed to determine whether different variables could predict which slowgrowing morulas develop into blastocysts. The variables included in the analysis were age, insemination methods, whether the morula was at day 5 or day 6 , and morula grading before vitrification. Morula grading was the only variable that was found to predict blastocyst formation (M2, odds ratio 0.305 ; 95\% confidence interval, 0.111- 
Table 1 Characteristics and outcomes of surplus morulas and frozen ET cycles

\begin{tabular}{|c|c|}
\hline Characteristics & Outcomes \\
\hline Age (year) & $35.8 \pm 3.8$ \\
\hline \multicolumn{2}{|l|}{ Infertility factor (\%) } \\
\hline Male factor & 26.2 \\
\hline Tubal factor & 29.2 \\
\hline Ovarian factor & 22.9 \\
\hline Multiple factors & 21.7 \\
\hline No. of FET cycles & 180 \\
\hline No. of FET cycles include only thawed morulas ${ }^{\text {a }}$ & 128 \\
\hline \multicolumn{2}{|l|}{ Insemination methods (\%) } \\
\hline Conventional insemination & 67.0 \\
\hline Intracytoplasmic sperm injection & 33.0 \\
\hline \multicolumn{2}{|l|}{ Endometrial preparation methods (\%) } \\
\hline Natural cycle & 17.8 \\
\hline Artificial hormone replacement & 82.2 \\
\hline No. of surplus morulas thawed & 347 \\
\hline \multicolumn{2}{|l|}{ Morula development stage at fresh cycle } \\
\hline No. of day 5 morulas (\%) & $329(94.8 \%)$ \\
\hline No. of day 6 morulas (\%) & $18(5.2 \%)$ \\
\hline \multicolumn{2}{|l|}{ Morula grading at fresh cycle } \\
\hline No. of M1 (\%) & $54(15.5 \%)$ \\
\hline No. of M2 (\%) & $138(39.8 \%)$ \\
\hline No. of M3 (\%) & $155(44.7 \%)$ \\
\hline Morula post-thaw survival rate (\%) & 79.3 \\
\hline Morula to blastocyst formation rate (\%) & 66.6 \\
\hline Morula to top-quality blastocyst formation rate (\%) & 23.6 \\
\hline No. of morulas thawed per FET cycle & $2.1 \pm 0.7$ \\
\hline No. of embryos transferred per FET cycle & $1.7 \pm 0.6$ \\
\hline Clinical pregnancy rate (\%) & $43 / 128=33.6 \%$ \\
\hline Implantation rate per transferred embryos (\%) & $51 / 220=23.2 \%$ \\
\hline Ongoing pregnancy rate (\%) & $35 / 128=27.3 \%$ \\
\hline Live birth rate (\%) & $29 / 128=22.7 \%$ \\
\hline Abortion rate (\%) & $7 / 43=16.3 \%$ \\
\hline Multiple pregnancy rate ${ }^{\mathrm{b}}(\%)$ & $7 / 43=16.3 \%$ \\
\hline
\end{tabular}

${ }^{a}$ Excluding cycles in which embryos transferred were from mixed frozenthawed blastocysts and cancelled cycles

${ }^{b}$ Including two sets of monozygotic twins

0.843. M3, odds ratio $0.114 ; 95 \%$ confidence interval, 0.042-0.311) (Table 3).

\section{Pregnancy outcomes}

When analyzing pregnancy outcomes, the 43 FET cycles in which thawed morulas were mixed with thawed blastocysts were excluded, as were the nine cancelled cycles. Pregnancy outcomes were therefore analyzed in the 128 FET cycles that included only morulas that underwent the freezing-thawing process. The clinical pregnancy rate per FET cycle was $33.6 \%$. The abortion rate was $16.3 \%$. The rate of multiple pregnancies was $16.3 \%$. Other pregnancy outcomes are summarized in Table 1. Of the 29 pregnancies that resulted in live births, six were from thawed day 5 M3 morulas. None of the embryos derived from thawed day 6 morulas resulted in a positive pregnancy outcome. The average numbers of blastocysts and top-quality blastocysts contained in transferred embryos were larger for the positive clinical pregnancy cycles $(n=43)$ than for the negative cycles $(n=85)$. There was no significant difference in cycles containing embryos from top-quality morulas (M1) and the numbers of total embryos transferred (Table 4).

\section{Discussion}

The study demonstrated the feasibility of freezing poorquality surplus morulas on day 5/day 6. Following thawing of the morulas and an additional day of culture, satisfactory survival and blastocyst formation rates were observed.

To our knowledge, the developmental potential of delayed or incompletely compacted morulas in frozenthawed cycles has never been systematically described. This pilot study revealed results obtained from surplus morulas, which showed a BFR as high as $66.6 \%$; this rate is comparable to the BFR of normally developed day 4 morulas during fresh cycles (68.5\%) [3]. Our study found that over one-half of heavily fragmented morulas (M3) could develop into blastocysts, which showed a higher BFR than what has been previously reported. In 2011, Ivec M et al. found the BFR of day 5 morulas to be $84 \%$ in the fresh cycle [9]. In poor-quality day 5 morulas (> 20\% fragments), the optimal (5AA at least) blastocyst formation rate was $13.6 \%$ [9]. Our surplus poor-quality day 5 morulas (>10\% fragments) had a $16.7 \%$ top-quality (3AA at least) blastocyst formation rate after the thawing procedure. The study details from previous publications discussing different conditions in morulas are summarized along with our pilot study results (See Additional file 1: Table S1).

Since the freezing-thawing strategy was modified, we focused on the development of heavily fragmented morulas following this procedure. The degree of embryo fragmentation is closely related to chromosome anomalies [14]. Fragmentation of cleavage stage embryos is an indicator of poor blastocyst development [11]. The presence of significant numbers of fragments, particularly in conjunction with discrepancies in blastomere symmetry, substantially reduces embryo viability and has a negative impact on clinical outcomes. Studies have suggested that if cellular fragmentation leads to apoptosis or limits the rate of blastomere cleavage, the removal of these fragments might improve cell division and implantation [13, 26]. The selection of human embryos that survive cryopreservation and continue to undergo cleavage in vitro 
Table 2 Day 5 and day 6 morulas and their ability for blastocyst development in the following 1 day of in vitro cultivation after freezing-thawing procedure

\begin{tabular}{|c|c|c|c|c|c|c|c|c|}
\hline & \multicolumn{4}{|c|}{ Day 5 morulas $(n=329)$} & \multicolumn{4}{|c|}{ Day 6 morulas $(n=18)$} \\
\hline & $\overline{M 1}$ & M2 & M3 & $P$ & M1 & M2 & M3 & $P$ \\
\hline Morula No. & 54 & 131 & 144 & & 0 & 7 & 11 & \\
\hline $\mathrm{BFR}^{\mathrm{a}}, \%$ & $48 / 54,88.9 \%$ & $97 / 131,74.0 \%$ & $76 / 144,52.8 \%$ & $<0.001$ & & $3 / 7,42.9 \%$ & $3 / 11,63.6 \%$ & NS \\
\hline Top $^{\mathrm{b}}$ BFR, $\%$ & $35 / 54,64.8 \%$ & $33 / 131,25.2 \%$ & $13 / 144,9.0 \%$ & $<0.001$ & & $0 / 70 \%$ & $1 / 119.1 \%$ & NS \\
\hline
\end{tabular}

${ }^{\mathrm{a} B F R}$ Blastocyst formation rate. ${ }^{\mathrm{b}}$ Top, $>3$ AA blastocysts. NS Not significant

has been shown to significantly improve the delivery rate [27]. It can be hypothesized that anucleate cell fragments that exhibit erratic distribution of the cell adhesion protein E-cadherin cannot survive the freezing-thawing procedures [13]. Moreover, laser-assisted hatching may benefit morulas by expelling fragmented debris and may improve cell division and blastocyst formation [7, 28]. We discovered that the fragments can be removed/released more easily with laser-assisted hatching after thawing (Fig. 1). Further study should explore whether this phenomenon can influence outcomes.

It may be an option to let the delayed morulas declare their growth capacity in fresh cycles, with increasing literature having demonstrated that day 6/7 blastocysts achieved live births [29-32]. However, concerning the earlier implantation window in the stimulated cycle, the slow-developing embryos often miss the synchronized endometrium and are cryopreserved [4, 5, 29]. Morula stage embryos have undergone genome activation [3]; referring to the adequate post-thaw BFRs, our policy of cryopreserving surplus morulas enabled the laboratory process and offered a flexible schedule for the following FET for both the couple and the clinicians. The manipulations and medical records of a couple can be completed on the same day in most circumstances, which reduces

Table 3 Regression analysis/prediction of the development of morulas to blastocysts

\begin{tabular}{|c|c|c|c|c|}
\hline \multirow[t]{2}{*}{ Variable } & \multirow[t]{2}{*}{ Significance } & \multirow[t]{2}{*}{ OR } & \multicolumn{2}{|c|}{$95 \% \mathrm{Cl}$ for OR } \\
\hline & & & Lower & Upper \\
\hline \multicolumn{5}{|l|}{ Morula grades } \\
\hline M1 & - & 1 & - & - \\
\hline M2 & 0.022 & 0.305 & 0.111 & 0.843 \\
\hline M3 & $<0.001$ & 0.114 & 0.042 & 0.311 \\
\hline Age & 0.137 & 0.950 & 0.888 & 1.016 \\
\hline \multicolumn{5}{|l|}{ Insemination method } \\
\hline Conventional IVF & - & 1 & - & - \\
\hline ICSI & 0.487 & 0.828 & 0.487 & 1.409 \\
\hline \multicolumn{5}{|l|}{ Compaction day } \\
\hline Day 5 & - & 1 & - & - \\
\hline Day 6 & 0.492 & 0.701 & 0.255 & 1.930 \\
\hline
\end{tabular}

mistakes. The morulas used in these studies were surplus, which indicated that most of the couples had other embryos frozen. The couples did not pay extra fees for vitrification and storage at our institution. Further randomized controlled studies may be required to compare the BFRs of day $5 / 6$ morulas in fresh and FET cycles and to explore the pregnancy outcomes following extended culture of surplus morulas after undergoing the freezing-thawing procedure (See Additional file 2: Table S2).

Unlike the day 3 cleavage and day 5 blastocyst stages, no consensus has been reached about the embryo morphological scoring criteria for morulas $[1,3,8,9,15,21,28$, 33]. This may have contributed to the neglect of morulas in research. A consensus has been reached about morphologic criteria at the blastocyst stage, with the transfer of good-quality blastocysts resulting in better implantation potential and better clinical outcomes than what is achieved with other blastocysts [34-36]. A sophisticated scoring system for morulas had a better predictive value than the traditional scoring system based on the day 3 cleavage stage [3]. The grading system proposed in the present study was based on compaction and fragmentation percentages. The BFR and top-quality BFR were significantly different and had a decreasing trend among M1 to M3 in day 5 morulas (Table 2). The predictive value for blastocyst formation was good, and the scoring principle was easy to remember (Table 3).

A higher aneuploidy rate has been reported in slowgrowing embryos [37]. Expanded blastocysts at day 5 had a higher chance of live birth rate than those at day 6 after thawed blastocyst transfer [38]. The embryo expansion day as well as the morphology need to be given full consideration when selecting embryos. During the study period, 18 day 6 morulas were thawed. Only one top-quality blastocyst was formed from these morulas, in which no positive pregnancy outcomes were reported. The aneuploidy rate of day 6 compacted morulas obtained during fresh cycles from women aged $>38$ years was $97 \%$ [31]. Further studies into the cost-effectiveness of biopsy and/or the vitrification of day 6 morulas are required, and the decision-making process should be shared with the patients.

In our study, we analyzed the post-thaw developmental potential of slow-growing poor-quality morulas. We graded the morulas and found a linear trend of the BFR 
Table $\mathbf{4}$ Characteristics of cycles with positive and negative clinical pregnancy

\begin{tabular}{|c|c|c|c|}
\hline Variable & Positive pregnancy, $n=43$ & Negative pregnancy, $n=85$ & $P$ \\
\hline Age, year & $35.8 \pm 3.2$ & $35.9 \pm 3.6$ & NS \\
\hline Endometrial preparation, hormone replacement, \% & 74.4 & 82.4 & NS \\
\hline Peak endometrium thickness, $\mathrm{cm}$ & $1.1 \pm 0.3$ & $1.1 \pm 0.2$ & NS \\
\hline Containing embryos from top morula (M1), n (\%) & $16(37.2)$ & $26(30.6)$ & NS \\
\hline No. of embryos transferred per cycle, $n$ & $1.8 \pm 0.6$ & $1.7 \pm 0.5$ & NS \\
\hline No. of blastocysts ${ }^{a}$ contained in transferred embryos & $1.7 \pm 0.7$ & $1.4 \pm 0.6$ & 0.023 \\
\hline No. of top blastocysts ${ }^{a}$ contained in transferred embryos & $0.9 \pm 0.7$ & $0.4 \pm 0.6$ & $<0.001$ \\
\hline
\end{tabular}

alastocysts developed from thawed morulas

NS Not significant

among M1, M2 and M3. However, this study had several limitations. First, embryo viability was assessed by morphology alone. Additional methods, such as morphokinetics and metabolism, may be incorporated into this strategy. Second, the embryo assessment is subjected to interoperator variability, and until now, there have been no objective methods or commercial tools available for measuring embryo fragments. Third, preimplantation genetic screening (PGS) was not applied to our cohort; therefore, the euploidy rate of these surplus morulas was unclear. Fourth, the costeffectiveness of this strategy was difficult to define, so further randomized controlled trials may be required (see Additional file 2: Table S2).

This proof-of-concept study indicates that the described strategy should not be overlooked and may be applicable to the schedule of high-volume IVF laboratories (i.e., the surplus embryos can be cryopreserved on the same day with fresh embryo transfer and

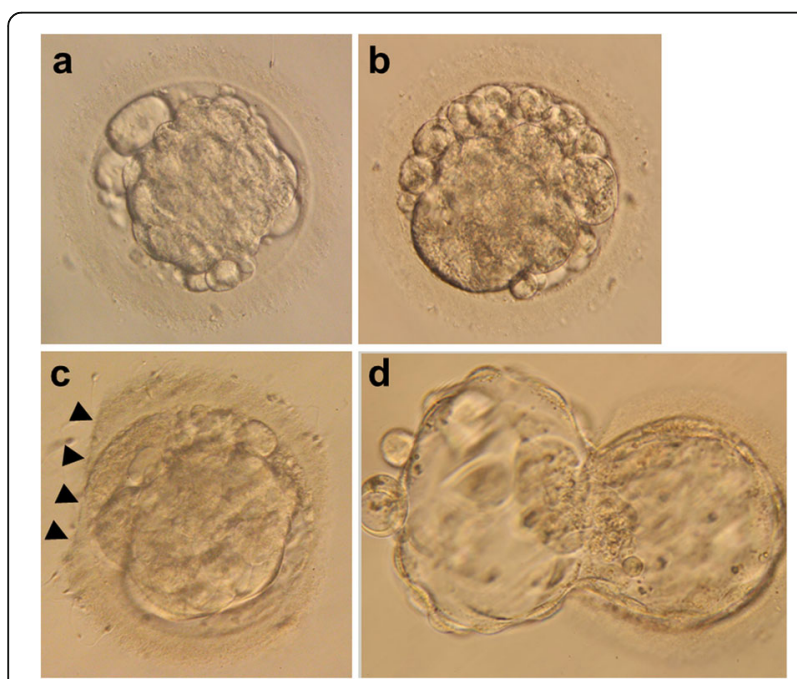

Fig. $1 \mathrm{M} 3$ morulas in different periods. a M3 morula in the fresh cycle just before vitrification. b M3 morula in the FET cycle immediately after thawing. c Thawed M3 morula after laser-assisted hatching; the straight dissection on the zona pellucida (arrowheads) is present. d 5AA blastocyst evolved from thawed M3 morula weekend work can be avoided). In clinical practice, programming is very convenient, both for physicians by facilitating their work schedules and for patients by enabling them to plan appointments. We suggest that the morulas be cryopreserved in separate containers from blastocysts to facilitate single embryo transfer (SET) or further cultivation. Regarding the high top-quality BFR of day 5 M1 morulas, we suggest cryopreserving them individually, which will prevent revitrification. In this study, we did not follow through with SET because the average age of the women was 35.8 years ( $>35$ years), there was a lack of PGS, and most of the outcomes from the fresh cycles proved to be a failure.

\section{Conclusions}

The post-thaw blastocyst formation rate was satisfactory, with approximately one-half of heavily fragmented morulas (M3) developing into blastocysts. Most of the poor-quality morulas were worth to freeze, with the reasonable goal of obtaining pregnancy and live birth. This alternative strategy may be a feasible approach for coping with poor-quality surplus morulas in non-PGS cycles.

\section{Supplementary information}

Supplementary information accompanies this paper at https://doi.org/10. 1186/s12958-019-0535-2.

Additional file 1: Table S1. Summary of literature review and our study about morula stage.

Additional file 2: Table S2. Proposals of future randomized controlled studies.

\section{Abbreviations}

BFR: Blastocyst formation rate; FET: Frozen embryo transfer; hCG: Human chorionic gonadotropin; ICSI: Intracytoplasmic sperm injection; IVF: In vitro fertilization; PGS: Preimplantation genetic screening; SET: Single embryo transfer

\section{Acknowledgments}

We thank the embryologists at Kaohsiung Chang Gung Memorial Hospital for their assistance. We acknowledge Registered Nurse Yun-Fang Chiang for 
assistance in patient registration and data collection. We thank Mr. Alex Raymond for assistance in English editing.

\section{Authors' contributions}

Conception and design of study: $\mathrm{KCL}_{\text {; }}$ analysis of data and writing of the manuscript: NCT, KCL; critical revision of the article for intellectual content: NCT, YTS, YJL, HJC, FJH, FTK, KCL. All authors read and approved the final manuscript.

\section{Funding}

This study was supported by CMRPG8G0071-73 and CMRPG8H0981 from Chang Gung Memorial Hospital.

\section{Availability of data and materials}

The datasets used and/or analyzed during the current study are available from the corresponding author on reasonable request.

\section{Ethics approval and consent to participate}

This study was approved by the Institutional Review Board of Chang Gung Memorial Hospital (Ref. No. 201800211B0 and No. 201900131B0).

\section{Consent for publication}

Not applicable.

\section{Competing interests}

The authors declare that they have no competing interests.

\section{Author details}

${ }^{1}$ Department of Obstetrics and Gynecology, Kaohsiung Chang Gung Memorial Hospital and Chang Gung University College of Medicine, 123 Ta-Pei Road, Niao-Sung District, Kaohsiung city, Taiwan. ${ }^{2}$ Graduate Institute of Clinical Medicine, College of Medicine, Kaohsiung Medical University, Kaohsiung, Taiwan. ${ }^{3}$ Department of Obstetrics and Gynecology, Xiamen Chang Gung Hospital, Xiamen, Fujian, China. ${ }^{4}$ Center for Menopause and Reproductive Medicine Research, Kaohsiung Chang Gung Memorial Hospital and Chang Gung University College of Medicine, Kaohsiung, Taiwan.

Received: 15 July 2019 Accepted: 15 October 2019

Published online: 30 October 2019

\section{References}

1. Hardarson T, Van Landuyt L, Jones G. The blastocyst. Hum Reprod. 2012; 27(Suppl 1):i72-91.

2. Weinerman R, Mainigi M. Why we should transfer frozen instead of fresh embryos: the translational rationale. Fertil Steril. 2014;102(1):10-8.

3. Fabozzi G, Alteri A, Rega E, Starita MF, Piscitelli C, Giannini P, et al Morphological assessment on day 4 and its prognostic power in selecting viable embryos for transfer. Zygote. 2016;24(4):477-84.

4. Haas J, Meriano J, Bassil R, Barzilay E, Zilberberg E, Casper RF. Developmental potential of slow-developing embryos: day-5 morulae compared with day-5 cavitating morulae. Fertil Steril. 2019;111(1):105-11.

5. Tannus S, Cohen Y, Henderson S, Al Ma'mari N, Shavit T, Son WY, et al. Fresh transfer of day 5 slow-growing embryos versus deferred transfer of vitrified, fully expanded day 6 blastocysts: which is the optimal approach? Hum Reprod. 2019;34(1):44-51.

6. Tao J, Tamis R, Fink K. Pregnancies achieved after transferring frozen morula/compact stage embryos. Fertil Steril. 2001;75(3):629-31.

7. Tao J, Tamis R, Fink K, Williams B, Nelson-White T, Craig R. The neglected morula/compact stage embryo transfer. Hum Reprod. 2002;17(6):1513-8.

8. Li RS, Hwu YM, Lee RK, Li SH, Lin MH. Day 4 good morula embryo transfer provided compatible live birth rate with day 5 blastocyst embryo in fresh IVF/ET cycles. Taiwan J Obstet Gynecol. 2018;57(1):52-7.

9. Ivec M, Kovacic B, Vlaisavljevic V. Prediction of human blastocyst development from morulas with delayed and/or incomplete compaction. Fertil Steril. 2011:96(6):1473-78.e2

10. Tao J, Craig RH, Johnson M, Williams B, Lewis W, White J, et al. Cryopreservation of human embryos at the morula stage and outcomes after transfer. Fertil Steril. 2004;82(1):108-18.

11. Stone BA, Greene J, Vargyas JM, Ringler GE, Marrs RP. Embryo fragmentation as a determinant of blastocyst development in vitro and pregnancy outcomes following embryo transfer. Am J Obstet Gynecol. 2005;192(6): 2014-9 discussion 19-20.

12. Keltz MD, Skorupski JC, Bradley K, Stein D. Predictors of embryo fragmentation and outcome after fragment removal in in vitro fertilization. Fertil Steril. 2006;86(2):321-4.

13. Fujimoto WY, Browne RW, Bloom MS, Sakkas D, Alikani M. Pathogenesis, developmental consequences, and clinical correlations of human embryo fragmentation. Fertil Steril. 2011;95(4):1197-204.

14. Bongso A, Ng SC, Lim J, Fong CY, Ratnam S. Preimplantation genetics: chromosomes of fragmented human embryos. Fertil Steril. 1991;56(1):66-70.

15. Lan KC, Huang FJ, Lin YC, Kung FT, Hsieh CH, Huang HW, et al. The predictive value of using a combined Z-score and day 3 embryo morphology score in the assessment of embryo survival on day 5. Hum Reprod. 2003;18(6):1299-306.

16. Lin PY, Huang FJ, Kung FT, Lin YC, Chiang HJ, Lin YJ, et al. Reassessing the feasibility of the zygote score for predicting embryo viability in IVF/ICSI using the $\mathrm{GnRH}$ antagonist protocol compared to the long protocol. PLoS One. 2017:12(2):e0171465.

17. Swain JE. Is there an optimal pH for culture media used in clinical IVF? Hum Reprod Update. 2012;18(3):333-9.

18. Mukaida T, Nakamura S, Tomiyama T, Wada S, Kasai M, Takahashi K. Successful birth after transfer of vitrified human blastocysts with use of a cryoloop containerless technique. Fertil Steril. 2001;76(3):618-20.

19. Lin PY, Huang FJ, Kung FT, Wang LJ, Chang SY, Lan KC. Comparison of the offspring sex ratio between fresh and vitrification-thawed blastocyst transfer. Fertil Steril. 2009;92(5):1764-6.

20. Mukaida T, Takahashi K, Kasai M. Blastocyst cryopreservation: ultrarapid vitrification using cryoloop technique. Reprod BioMed Online. 2003:6(2):221-5.

21. Heitmann RJ, Hill MJ, Richter KS, DeCherney AH, Widra EA. The simplified SART embryo scoring system is highly correlated to implantation and live birth in single blastocyst transfers. J Assist Reprod Genet. 2013:30(4):563-7.

22. Gardner DK, Schoolcraft WB. Culture and transfer of human blastocysts. Curr Opin Obstet Gynecol. 1999:11(3):307-11.

23. Lan KC, Huang FJ, Lin YC, Kung FT, Chang SY. Zona-free versus laser zonaassisted hatching blastocyst transfer: a comparison of outcomes. Fertil Steril. 2009;91(5):1959-62.

24. Kung FT, Lin YC, Tseng YJ, Huang FJ, Tsai MY, Chang SY. Transfer of frozenthawed blastocysts that underwent quarter laser-assisted hatching at the day 3 cleaving stage before freezing. Fertil Steril. 2003;79(4):893-9.

25. Zegers-Hochschild F, Adamson GD, de Mouzon J, Ishihara O, Mansour R, Nygren K, et al. International Committee for Monitoring Assisted Reproductive Technology (ICMART) and the World Health Organization (WHO) revised glossary of ART terminology, 2009. Fertil Steril. 2009;92(5):1520-4.

26. Alikani M, Cohen J, Tomkin G, Garrisi GJ, Mack C, Scott RT. Human embryo fragmentation in vitro and its implications for pregnancy and implantation. Fertil Steril. 1999:71(5):836-42.

27. Van der Elst J, Van den Abbeel E, Vitrier S, Camus M, Devroey P, Van Steirteghem AC. Selective transfer of cryopreserved human embryos with further cleavage after thawing increases delivery and implantation rates. Hum Reprod. 1997:12(7):1513-21.

28. Ebner T, Moser M, Shebl O, Sommergruber M, Gaiswinkler U, Tews G. Morphological analysis at compacting stage is a valuable prognostic tool for ICSI patients. Reprod BioMed Online. 2009;18(1):61-6.

29. Murata Y, Oku H, Morimoto Y, Tokuda M, Murata T, Sugihara K, et al. Freezethaw programmes rescue the implantation of day 6 blastocysts. Reprod BioMed Online. 2005:11(4):428-33.

30. Kovalevsky G, Carney SM, Morrison LS, Boylan CF, Neithardt AB, Feinberg RF. Should embryos developing to blastocysts on day 7 be cryopreserved and transferred: an analysis of pregnancy and implantation rates. Fertil Steril. 2013; 100(4):1008-12.

31. Irani M, Zaninovic N, Canon C, O'Neill C, Gunnala V, Zhan Q, et al. A rationale for biopsying embryos reaching the morula stage on day 6 in women undergoing preimplantation genetic testing for aneuploidy. Hum Reprod. 2018:33(5):935-41.

32. Hammond ER, Cree LM, Morbeck DE. Should extended blastocyst culture include day 7? Hum Reprod. 2018;33(6):991-7.

33. Alpha Scientists in Reproductive M, Embryology ESIGo. The Istanbul consensus workshop on embryo assessment: proceedings of an expert meeting. Hum Reprod. 2011:26(6):1270-83.

34. Gardner DK, Schoolcraft WB, Wagley L, Schlenker T, Stevens J, Hesla J. A prospective randomized trial of blastocyst culture and transfer in in-vitro fertilization. Hum Reprod. 1998;13(12):3434-40. 
35. Gardner DK, Vella P, Lane M, Wagley L, Schlenker T, Schoolcraft WB. Culture and transfer of human blastocysts increases implantation rates and reduces the need for multiple embryo transfers. Fertil Steril. 1998;69(1):84-8.

36. Irani M, Reichman D, Robles A, Melnick A, Davis O, Zaninovic N, et al. Morphologic grading of euploid blastocysts influences implantation and ongoing pregnancy rates. Fertil Steril. 2017;107(3):664-70.

37. Taylor TH, Patrick JL, Gitlin SA, Wilson JM, Crain JL, Griffin DK. Comparison of aneuploidy, pregnancy and live birth rates between day 5 and day 6 blastocysts. Reprod BioMed Online. 2014;29(3):305-10.

38. Ferreux L, Bourdon M, Sallem A, Santulli P, Barraud-Lange V, Le Foll N, et al. Live birth rate following frozen-thawed blastocyst transfer is higher with blastocysts expanded on day 5 than on day 6. Hum Reprod. 2018;33(3):390-8.

\section{Publisher's Note}

Springer Nature remains neutral with regard to jurisdictional claims in published maps and institutional affiliations.

Ready to submit your research? Choose BMC and benefit from:

- fast, convenient online submission

- thorough peer review by experienced researchers in your field

- rapid publication on acceptance

- support for research data, including large and complex data types

- gold Open Access which fosters wider collaboration and increased citations

- maximum visibility for your research: over $100 \mathrm{M}$ website views per year

At $\mathrm{BMC}$, research is always in progress.

Learn more biomedcentral.com/submissions 